National Park (1670 sq $\mathrm{km})$ in the extreme south; Barail National Park (790 sq km) and North Karbi Anglong Sanctuary (700 sq km) in central Assam; and Bharali National Park $(720 \mathrm{sq} \mathrm{km})$ in northern Sonitpur. The latter areas also includes Nameri Sanctuary.

Habitats in all these areas are mostly tropical evergreen and semi-evergreen forests. In the higher areas of the Barails the forest is subtropical evergreen. All the proposed reserves have good tiger Panthera tigris and leopard $P$. pardus populations, which are sympatric with the clouded leopard throughout north-eastern India. Guwahati 781 007, Assam, India.
References

Choudhury, A.U. 1989. Primates of Assam: their Distribution, Habitat and Status. Ph.D. thesis, Gauhati University, 300 pp.

Dinerstein, E. and Mehta, J.N. 1989. The clouded leopard in Nepal. Oryx, 23, 199-201.

IUCN, 1990. 1990 Red List of Threatened Animals. IUCN, Gland, Switzerland and Cambridge, UK.

Rabinowitz, A. 1988. The clouded leopard in Taiwan. Oryx, 22, 46-47.

Rabinowitz, A., Andau, P. and Chai, P.P.K. 1987. The clouded leopard in Malaysian Borneo. Oryx, 21, 107-111.

Santiapillai, C. and Ashby, K.R. 1988. The clouded leopard in Sumatra. Oryx, 22, 44-45.

\title{
Problems of wild elephant translocation
}

When wild animals cause problems for people living nearby, moving the animals to a safe place elsewhere may appear to be an attractive solution. However, experience in India has shown that it is far from ideal when Asian elephants are involved and the usefuleness of translocation as a management tool for this species has to be questioned.

\section{Introduction}

Reducing man-elephant conflicts is a major concern of wildlife managers in elephantholding areas. Translocating wild elephants by motor transport under sedation, after initial chemical immobilization, is one preventive measure used to contain man-elephant conflict and has been attempted with Asian elephants in Sri Lanka, Malaysia, and India (Karnataka and West Bengal).

In 1979 the Sri Lanka Department of Wildlife Conservation translocated 10 elephants from Deduru Oya to Wilpattu National Park situated to the north of Colombo, about $120 \mathrm{~km}$ from the point of capture (Hofmeyr,
1979). Since 1974 the Department of Wildlife Conservation and National Parks, Peninsular Malaysia, has been translocating elephants from areas opened up for oil-palm plantations to safer areas of undisturbed forest and by January 1988 had thus removed 132 elephants (Kahn, 1987; Lahiri-Choudhury, 1990). In 1987 Karnataka Forest Department, India, translocated seven elephants, including a killer rogue tusker, from Madikere Forest Division to Nagarhole National Park, $105 \mathrm{~km}$ from the point of capture. It also moved one elephant from the same vicinity to Dubara, $60 \mathrm{~km}$ away (Appayya, undated). Later Karnataka Forest Department reportedly translocated 12 more elephants in the same manner.

\section{A case of homing}

In July 1988 West Bengal Forest Directorate translocated a rogue tusker (height $2.45 \mathrm{~m}$ ) from the westernmost fringe of northern Bengal to the core area of recently created Buxa Tiger Reserve on the easternmost fringe of the same forest belt, a distance of $180 \mathrm{~km}$ 


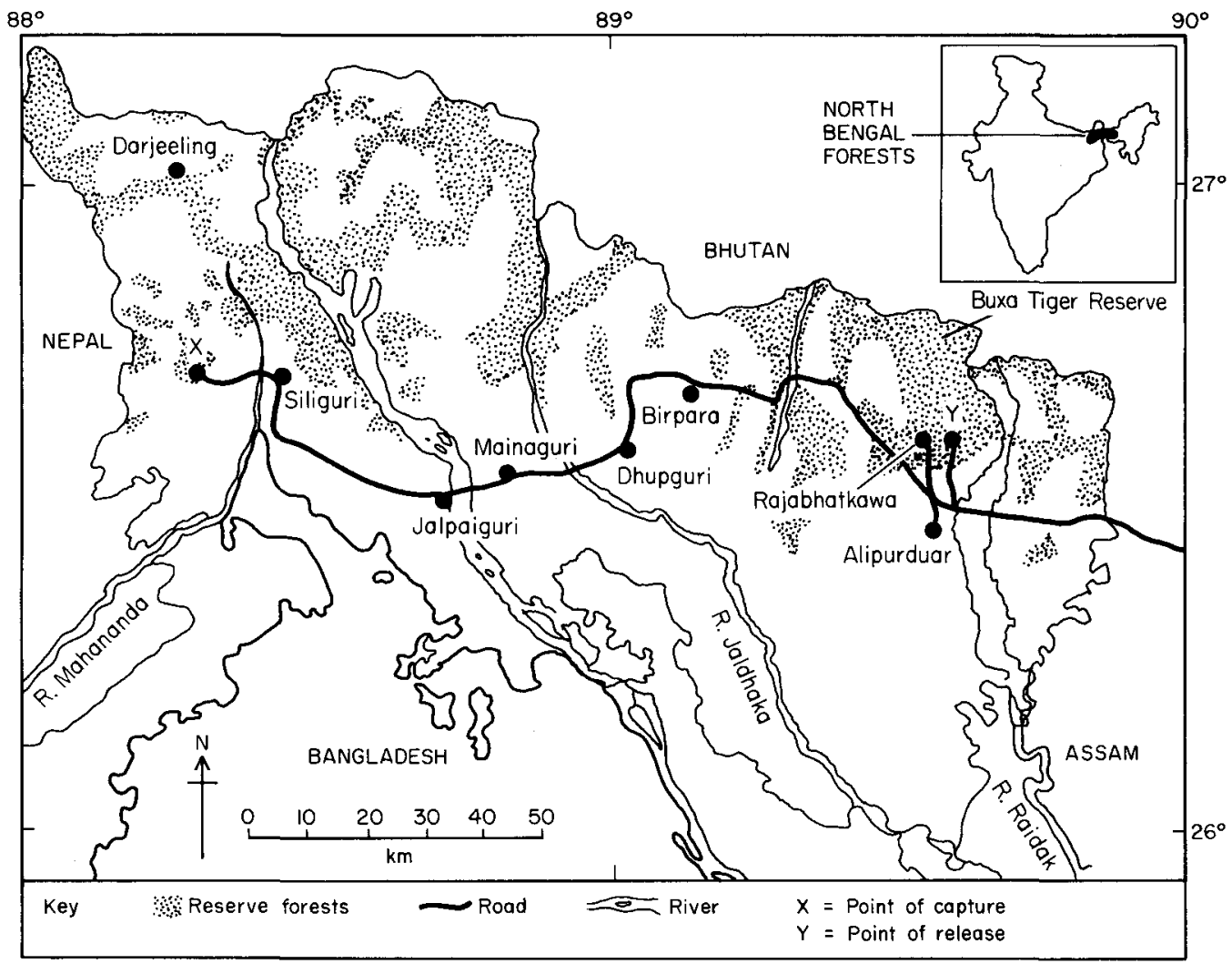

Figure 1. North Bengal showing forest and the locations of capture and release of a rogue elephant.

(Lahiri-Choudhury, 1988) (Figure 1).

This elephant, however, returned to the original location of capture within 3 weeks of its release, travelling along elephant tracks criss-crossing a mosaic of forests and human settlements, covering a far greater distance than the $180 \mathrm{~km}$ it been carried on a lorry (Lahiri-Choudhury, 1991). Judging by the size of the footprints and the dates involved, it was in all likelihood responsible for killing at least two people and injuring another on its return journey. Initially, when reports came in of depredations by the 'same elephant' in the same area where it had been causing trouble earlier, the Forest Department dismissed them. It was unbelievable that an elephant could return from that distance, a journey that probably involved covering a total of $300 \mathrm{~km}$. The elephant died soon after its return and was conclusively identified by one of the jute ropes used in its earlier capture, which was still tied around its neck.

\section{Discussion}

The experience indicates that translocation was not a solution to the problem in this particular case. Hofmeyr (1979) also reported that definitely one and probably more elephants translocated in Sri Lanka returned to where they had been captured. Most of the elephants translocated in Karnataka returned. Two elephants translocated in 1988 in southern India and released in a different and separate forest area showed signs of disorientation and had to be recaptured and domesticated (V. Krishnamurthy, pers. comm.). Because of the difficult terrain there has been no post-release monitoring of the movement of translocated 
elephants in Malaysia (Rice, 1990; L. Ratnam and S. Daim, pers comm.).

The usefulness of translocation as a management tool in such cases thus appears to be in serious doubt and further investigation is needed. Accordingly, it has been proposed by the present writer that the Wildlife Institute of India should carry out the following research:

(i) Monitoring movements of elephants after translocation in contiguous forest areas with the help of radio-telemetry.

(ii) Verifying if the matriarch (or some other animal of a different age-group) from a herd, translocated but kept tethered at the release point, could bring back the herd to that area as a response to the infrasonic distress calls emitted by the captured animal. If successful, this could be a useful tool to guide straying elephant herds, an increasingly frequent phenomenon in India, back to their normal home range (Panwar and Johnsingh, 1989).

(iii) All reported cases of return of translocated elephants concern animals removed from their original home range. It needs to be ascertained whether the same behaviour pattern would occur when straying herds are translocated back to their original home range.]

\section{K. Lahiri-Choudhury 45 Suhasini Ganguly Sarani Calcutta 700 025, India}

\section{References}

Appayya, M.K. Undated. Operation Elephant Translocation. Mimeo. Karnakata Forest Department, India. 6pp.

Hofmeyr, J.M. 1979. Diary of the Deduru Oya Elephant Capture, Sri Lanka 1979. Unpublished mimeo reprint. $35 \mathrm{pp}$.

Khan, M.B.M.K. 1987. The status, distribution and conservation of elephant in Peninsular Malaysia. In Action Plan for Asian Elephant Conservation (draft) (Compiler, C. Santiapillai). World Wide Fund for Nature, Switzerland.

Lahiri-Choudhury, D.K. 1988. Aggression in young elephants. Hornbill, 1988 (2), 28-39.

Lahiri-Choudhury, D.K. 1990. Translocating elephants. The India Magazine, 10, 12-21.

Lahiri-Choudhury, D.K. 1991. Translocation of Wild Elephants. Technical Report No. 1. Asian Elephant Conservation Centre of IUCN/SSC. Asian Elephant Specialist Group, Bangalore.

Panwar, H.S. and Johnsingh, A.J.T. 1989. Elephant Conservation in India: Problems and Prospects. Wildlife Institute of India, Dehra Dun, Uttar Pradesh, India. Mimeo. 26 pp.

Rice, C. 1990. Don't forget to pack the trunk. Wildlife Conservation, 93 (4), 58-67.

\section{Monkey business in Gibraltar}

The population of Barbary macaques Macaca sylvanus in Gibraltar, described as a 'unique colony of a Vulnerable species' (IUCN, 1988), is still at risk despite attempts to improve its prospects.

There are now approximately 105 macaques in Gibraltar, living in two main areas, Middle Hill and Queen's Gate. Since 1972 only the latter colony has been accessible to visitors and this has borne the brunt of tourism. Since 1985, when the land-frontier with Spain was fully opened, visitor numbers have increased almost fourfold. In the peak summer months about 1000 people a day visit the 31 monkeys at Queen's Gate (Fa, 1991).

There have been concerns about the impact of tourism on the macaques for many years. Particularly worrying is the fact that tourists offer the animals sweets and other unsuitable foods, which causes obesity and dental decay and has been linked to a lowered birth-rate and reduced lifespan (Fa, 1984, 1988). Both the military authorities, traditionally in charge of the monkeys, and biologists recognized the need to limit feeding of unsuitable foods and to improve visitor-monkey contact conditions (Fa, 1984; Carver, 1987). 